\title{
Theoretical Framework of Performance Indicators with BSC for the Private Higher Education Institution
}

\author{
Átila de Melo Lira, Irenilza de Alencar Naas \\ ${ }^{1}$ Paulista University/ UNIP, São Paulo Brazil \\ atilalira@hotmail.com
}

\begin{abstract}
Analyzing the performance of an organization requires the use of indicators. In recent decades, an indicator in particular has highlighted, the balanced socorecard (BSC). Therefore, a type of company specific, private higher education institutions (HEI's), has received little attention in research in this area, especially in how is the process of applying these indicators. Thus, this study aims to understand how is the balanced score card application process on a private higher education institution. For this, this study drew on research built by authors who discuss this application, in order to develop a theoretical framework, demonstrating how this process occurs. So, theoretical contributions were generated by this study with the analysis of other theoretical contributions of more extensive research, in which they individually could not handle to fill this theoretical gap in the literature.
\end{abstract}

Keywords: Balanced scorecard · Performance indicators · Private higher education institution

\section{Introduction}

The administrative process goes through stages ranging from planning to control the activities that are developed within an organization. In this sense, with the control we seek to correct flaws and distortions that have occurred along the production and management operations of the company. Therefore, it is necessary that performance indicators are applied within the organization to measure whether it can achieve the proposed organizational goals initially [1].

There are several types of performance indicators. Among them, one has won a special mention in recent decades, the Balanced Scorecard (BSC). It is in a strategic management tool that seeks to measure organizational performance based on four perspectives: financial, learning and growth, internal processes and client $[2,3,4]$.

The financial perspective is related to the long-term financial goals, involving measures profitability, contribution margin, breakeven, shareholder return, return on time investment, among others. This perspective has its own complexity to involve a number of dimensions and stakeholders. It will provide the necessary capital support for the development of other perspectives $[2,3,4]$.

adfa, p. 1, 2011.

(C) Springer-Verlag Berlin Heidelberg 2011 
With regard to the customer's perspective, it deals with issues involving the central agent of the business, the company's mission, that is, for whom it will seek to sell their products or services. It involves issues related to answer the most appropriate market segment and have a mix of: price, place, promotion and product to this market segment chosen through well-defined positioning strategies [2,3,4].

Regarding the internal process perspective, it represents the entire measurement of the production and management operations of the organization. Still, it involves the company's entire value chain, from the search for raw materials to after-sales. In addition, it has three steps: a) the process of innovation, which is to always seek to create new products that meet the needs and desires of customers; b) the operational process, which involves all the production and marketing of products or services to the customer; and c) the process of after-sales service, which has to evaluate customer satisfaction and accompany you to identify potential failures during the previous steps and make appropriate changes $[2,3,4]$.

The learning and growth perspective involves people in the organization, the development of an appropriate infrastructure so that they are able to well perform their duties, issues concerning the motivation of the employees so that they maintain their ongoing performance and also empowerment to they feel increasingly part of the company. In this perspective, it is also present aspects related to training and development of people working in the organization $[2,3,4]$.

In addition, we see the importance of analyzing a type of organization in particular that has singularities given its level of complexity management, higher education institutions (HEIs). This business segment has specific data dilemmas that occur in the decision-making process involved two dimensions that go in opposite directions, financial efficiency and quality in education [5,6,7,8,9].

Thus, seeking to answer the question: how does the application of BSC in a private HEI? This study aims to understand how is the balanced scorecard application process on a private higher education institution.

To meet the objective of this study, it proposed a theoretical framework that has nine steps. From step 1 to step 4, presents a inter-functional model of the BSC implementation of a private institution. Step 5 shows the influence of the sustainability category of the BSC on the financial perspective. Step 6 shows the impact of the decision-making process in institutional management. And the steps 7,8 and 9 show the implications of issues related to BSC adaptations during the feedback of the inter-functional model. Thus, following the proposal in detail.

\section{Theoretical Framework}

As the figure below, in the center of the proposed framework, it is shown the BSC application process in a private institution. Following the sustainability of BSC shall involve in matters concerning the financial management of the same. Then the decisionmaking process has implications for institutional management. 
In addition, the end of the BSC implementation process in a private institution, it does not end, continuous-become something that feeds back. During this feedback, the BSC can be adapted to the HEI thereafter begin to arise difficulties and adaptation dilemmas, and finally make modifications without losing the gist of the BSC assumptions, to the BSC application process restarts.

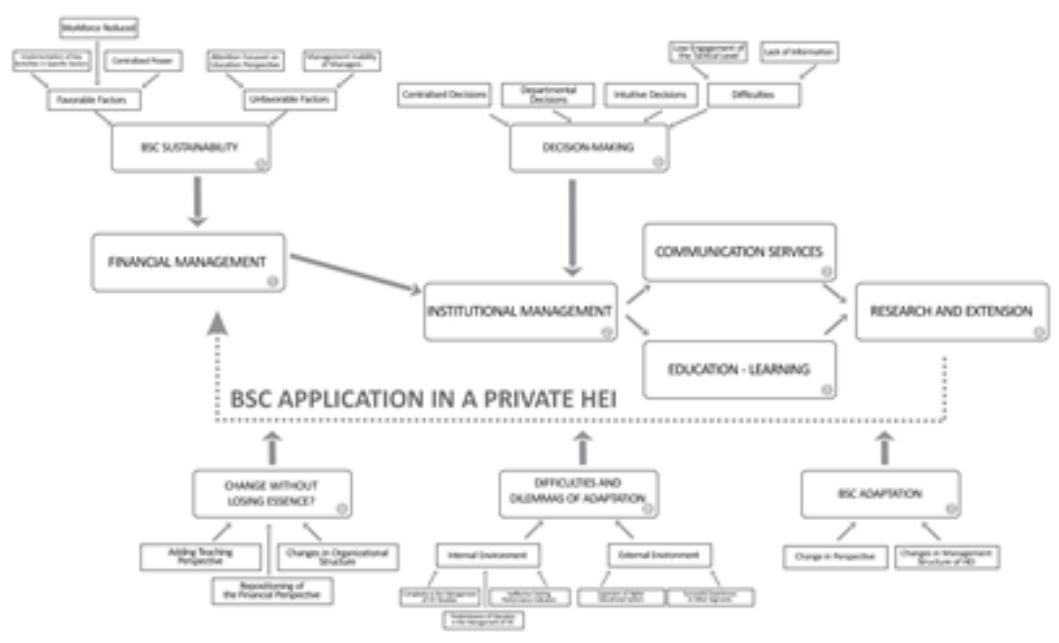

Fig. 1. Theoretical framework of performance indicators with balanced scorecard for the private Higher Education Institution

The first steps of the framework describe the application of BSC in a private HEI, by an inter-functional model performance. The proposed model supports the view that the starting point of the flow that involves activities and performance indicators starts from the financial management of the institution. The proposal is that effective financial management, characterized by solvency of finance, it is essential to ensure the development of a private educational institution. In turn, an appropriate institutional management, ie when coordinators and directors act effectively in carrying out its functions, and sectors such as library, laboratories and offices are directed to the needs of students the quality of teaching activities - learning and service communication emanate as a direct consequence [10].

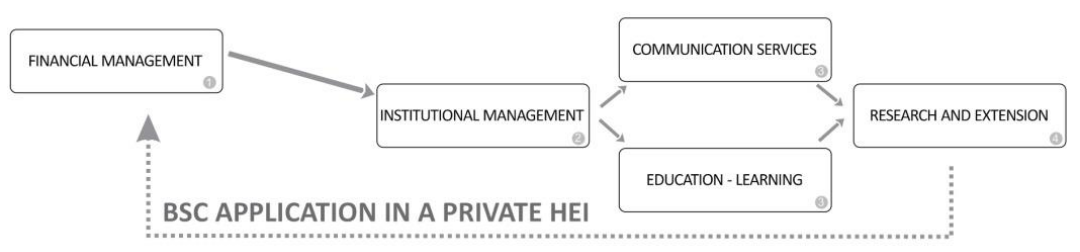

Fig. 2. Inter-functional model of BSC application in a private HEI 
These two combined functions converge in research and extension activities, ie, good internal communication tools, combined with educational incentives - learning are fundamental to foster the adoption of research and extension activities by universities. Because it is a private institution, the combination of all of these activities, developed satisfactorily provide profitable results financially, which leads back to the beginning of the model where these financial incomes will be managed in order to provide the continuity of the institution's activities. This feature justifies the flow of character given to the proposed model [10].

The later stage of the framework seeks to show that the financial management of inter-functional model is influenced by aspects of sustainability of the BSC. The analysis of institutional data (report of the committee for assessment, annual results records and financial statements of the institutions), allowed the identification of favorable and unfavorable factors to the sustainability of BSC in Brazilian HEI's. Among the favorable aspects are centralized power, reduced workforce and the implementation of key activities in specific sectors. But among the unfavorable aspects, present focused attention on the teaching perspective and the managerial inability of the managers [11].

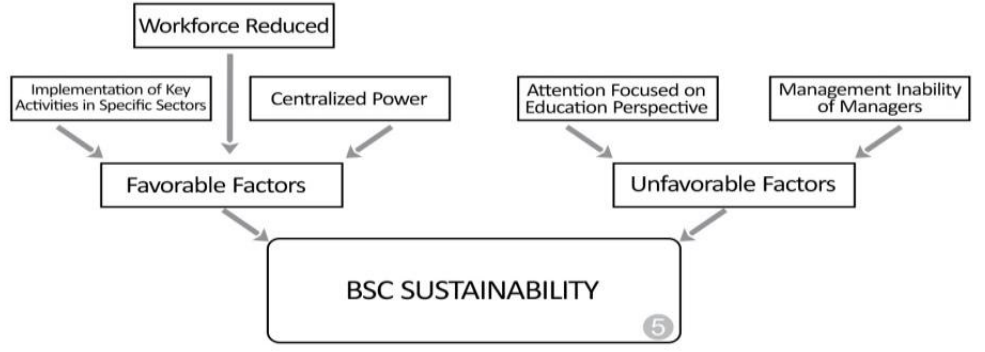

Fig. 3. BSC Sustainability

Then he sought to demonstrate that the process of decision-making can influence the institutional management. This process is characterized by a centralization of decisions, decisions are taken departmental way, they get to be intuitive, at certain times, and have difficulties related to low engagement technical level and the lack of information [12].

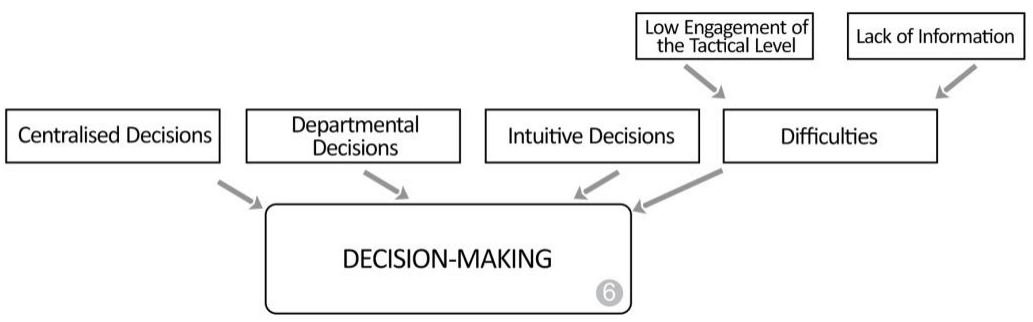

Fig. 4. The decision-making process in a private HEI 
Already during the feedback phase of the inter-functional model, an adaptation of the BSC is important to note the difficulties and dilemmas of adaptation and change without losing the essence of the BSC. During the adjustment, may be changes in traditional perspectives (financial, customer, internal processes and learning and growth) to ensure the effectiveness of this strategic model. There may also be changes in the management structure of the IES to correct deficiencies that come true to the complexity of the method [13].

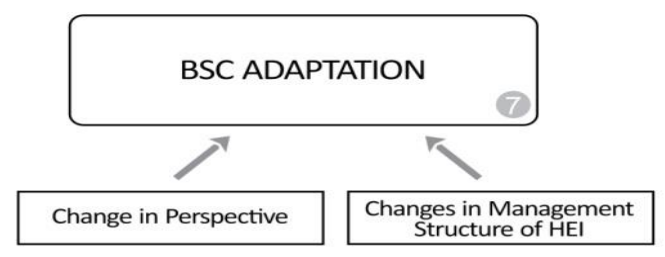

Fig. 5. BSC adaptation of a private HEI

With this, there are difficulties and dilemmas for adaptation, such as adapting the method to the institution or the institution of the method? These issues involve an analysis: a) the internal environment due to complexity in the management of Brazilian HEI's, the ineffectiveness of existing performance indicators and the prevalence of educators in the management of HEI; and b) the external environment due to expansion of the higher educational system and other successful experiences in other segments. Thus, the response indicates that the changes should be undertaken together [14].

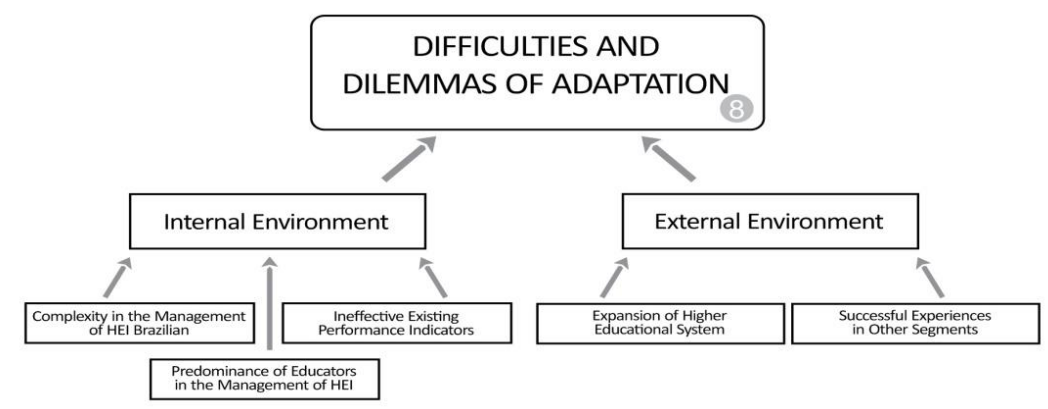

Fig. 6. Difficulties and dilemmas of BSC adaptation

Finally, during the implementation of these modifications should be changed without losing the gist of traditional BSC philosophy? The results indicate that for the HEI's successfully obtain the BSC is necessary that they modify this approach such that gets away from its traditional approach. Thus, within the context of HEI's analyzed, it is clear that these organizations gain greater successes in their activities when they leave 
the method as originally proposed and operationalize differently. Therefore, it is important to increase the education perspective, changes in organizational structure and repositioning of the financial perspective (given that the teaching perspective becomes the focus) [15].

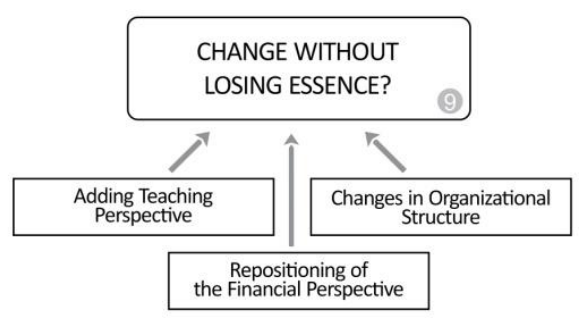

Fig. 7. Change without losing essence?

\section{Conclusion}

This study aims to understand how is the balanced score card application process on a private higher education institution. The first four steps can be carried out by means of a functional model performance. This model has as its starting point the financial management that supports the institutional management can carry out its tasks. The latter has a direct influence on teaching and learning operations and communication services, which together will result in research and extension activities of HEI.

Further, it is clear that to occur the sustainability of the process of the application, in the long run should be noted the favorable and unfavorable factors to it. This sustainability has direct implications on the financial management of the institution.

Another step corresponds to the decision-making that has features such as: centralized decisions, departmental decisions, intuitive decisions and difficulties of lack of information and low engagement tactical level. This step can directly influence the institutional management.

Finally, this internally-functional model needs to have a feedback loop which is made by the BSC adaptation step to correct possible distortions arising during application. Then we have the difficulties and dilemmas of adaptation and the last stage of modification by changing the traditional essence of the BSC, mainly due to the inclusion of the teaching perspective and changes in the management structure.

\section{References}

1. Miles, R.E., Snow, C.C., Meyer, A.D., Coleman, H.J.: Organizational Strategy, Structure, And Process. Academy of Management Review. 3, 546-562 (1978)

2. Kaplan, R.S., Norton, D.P.: The balanced scorecard. Harvard Business School Press, Boston (1996) 
3. Kaplan, R.S., Norton, D.P.: The Balanced Scorecard: Measures That Drive Perfomance. Harvard Business Review. 70, 71-79 (1992)

4. Kaplan, R.S., Norton, D.P.: The Balanced Scorecard: Translating Strategy into Action. Harvard Business school press, Boston (1997)

5. Beard, D.F.: Successful Applications of the Balanced Scorecard in Higher Education. Journal of Education for Business. 84, 275-282 (2009)

6. Chen, S.H., Yang, C.C., Shiau, J.Y.: The Application of Balanced Scorecard in The Performance Evaluation of Higher Education. The TQM Magazine. 18, 190-205 (2006)

7. Cullen, J., Joyce, J., Hassall, T., Broadbent, M.: Quality in Higher Education: From Monitoring to Management. Quality Assurance in Education, 11, 5-14 (2003)

8. Stewart, A.C., Carpenter-Hubin, J.: The Balanced Scorecard: Beyond Reports and Rankings. Planning for Higher Education, 29, 37-42 (2001)

9. Umashankar, V., Dutta, K.: Balanced Scorecards in Managing Higher Education Institutions: An Indian Perspective. International Journal of Educational Management, 21, 54-67 (2007)

10. Lira, Á.M., Naas, I.A.: Performance Indicators Applied to Brazilian Private Educational Institutions. Independent Journal of Management \& Production. 6, 286-298 (2015)

11. Rodrigues, T.K.A., Lira, Á.M., Naas, I.A., Oliveira, D.M.S.: Sustainability of Balanced Scorecard: An Analysis in the Context of Brazilian Higher Education Institutions. In POMS 2015, Washington (2015)

12. Rodrigues, T.K.A., Lira, Á.M., Naas, I.A.: The Balanced Scorecard (BSC) in Higher Education Institutions (HEI's): A Management Improvement Strategy. POMS 2015 Proceedings CD, Washington (2015)

13. Rodrigues, T.K.A., Lira, Á.M., Naas, I.A.: Adaptation of the Balanced Scorecard (BSC) to the Context of Higher Education Institutions (HEI's) Brazil. POMS 2015 Proceedings CD, Washington (2015)

14. Rodrigues, T.K.A., Lira, Á.M., Naas, I.A., Oliveira, D.M.S.: Difficulties and Dilemmas of Adaptation: The Balanced Scorecard in the Context of Brazilian HEI's. POMS 2015 Proceedings CD, Washington (2015)

Rodrigues, T.K.A., Lira, Á.M., Naas, I.A.: Changing Without Losing the Essence? A Study of BSC Adaptation at Brazilian Higher Education Institutions. POMS 2015 Proceedings CD, Washington (2015) 